\section{BRAZIULIAN JOURNAL}

OF MEDICAL AND BIOLOGICAL RESHARCH

www.bjournal.com.br
ISSN 0100-879X

Volume 43 (01) 1-123 January 2010

BIOMEDICAL SCIENCES

AND

CLINICAL INVESTIGATION

Braz J Med Biol Res, J anuary 2010, Volume 43(1) 68-76

Effect of aging and oral tolerance on dendritic cell function

P.U. Simioni, L.G.R. Fernandes, D.L. Gabriel and W.M.S.C. Tamashiro

The Brazilian Journal of Medical and Biological Research is partially financed by
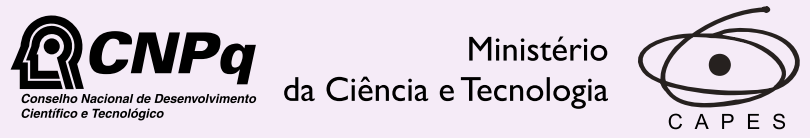

Ministério da Educação

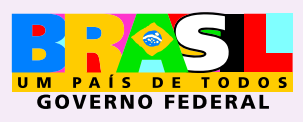

Institutional Sponsors 


\title{
Effect of aging and oral tolerance on dendritic cell function
}

\author{
P.U. Simioni, L.G.R. Fernandes, D.L. Gabriel and W.M.S.C. Tamashiro \\ Departamento de Microbiologia e Imunologia, Instituto de Biologia, Universidade Estadual de Campinas, \\ Campinas, SP, Brasil
}

\begin{abstract}
Oral tolerance can be induced in some mouse strains by gavage or spontaneous ingestion of dietary antigens. In the present study, we determined the influence of aging and oral tolerance on the secretion of co-stimulatory molecules by dendritic cells (DC), and on the ability of DC to induce proliferation and cytokine secretion by naive T cells from BALB/c and OVA transgenic (DO11.10) mice. We observed that oral tolerance could be induced in BALB/c mice ( $\mathrm{N}=5$ in each group) of all ages (8, 20, 40,60 , and 80 weeks old), although a decline in specific antibody levels was observed in the sera of both tolerized and immunized mice with advancing age (40 to 80 weeks old). DC obtained from young, adult and middle-aged ( 8,20 , and 40 weeks old) tolerized mice were less efficient $(65,17$ and $20 \%$, respectively) than DC from immunized mice $(P<0.05)$ in inducing antigen-specific proliferation of naive T cells from both BALB/c and DO11.10 young mice, or in stimulating IFN- $\gamma$, IL-4 and IL-10 production. However, TGF- $\beta$ levels were significantly elevated in co-cultures carried out with DC from tolerant mice $(P<0.05)$. DC from both immunized and tolerized old and very old (60 and 80 weeks old) mice were equally ineffective in inducing T cell proliferation and cytokine production $(P<0.05)$. A marked reduction in CD86 ${ }^{+}$marker expression was observed in $D C$ isolated from both old and tolerized mice ( 75 and $50 \%$, respectively). The results indicate that the aging process does not interfere with the establishment of oral tolerance in BALB/c mice, but reduces DC functions, probably due to the decline of the expression of the CD86 surface marker.
\end{abstract}

Key words: Oral tolerance; Dendritic cell; Antibody; Proliferation; Cytokine secretion

\section{Introduction}

Dendritic cells (DC) are the main antigen-presenting cells involved in the initiation of the immune response against exogenous antigens by stimulating naive $T$ cells (1), but they have also been associated with the deletion or silencing of auto-reactive lymphocytes that leads to central and/or peripheral tolerance (2-4). In the context of tolerance, DC play an important role in the responses to exogenous antigens, mainly to dietary proteins, and in the inhibition of auto-reactive $T$ cells that have escaped negative selection in the thymus $(2,3)$.

Dendritic cells are able to produce IL-12 in response to inflammatory stimuli, thus leading to $T$ helper (Th) cell differentiation to Th1. However, in microenvironments containing IL-10, the production of IL-12 is inhibited $(5,6)$. It has been shown that DC generated from human peripheral blood can assume a tolerogenic function after treatment with IL-10, inhibiting allogenic mixed leukocyte reactions and the anti-CD3-induced response of primed and naive $\mathrm{CD}^{+} \mathrm{T}$ cells (6).
The blockage of the co-stimulatory molecule, CD86, or its binding to CTLA-4 receptors on lymphocytes, rather than its interaction with CD28, seems to induce oral tolerance by inhibiting the secretion of transforming-growth factor beta (TGF- $\beta$ ) (7). However, other studies have shown that $\mathrm{DC}$ obtained from the gastrointestinal tract of mice do not present variations in the expression of the CD80 and CD86 molecules in oral tolerance or in priming with the antigen (8).

Senescence of the immune system leads to a decline in the responses to exogenous antigens as well as in the susceptibility to tolerance (9-11). The alterations observed in immunosenescence are attributed, at least in part, to the changes in maturation of $\mathrm{T}$ and $\mathrm{B}$ lymphocytes $(11,12)$. However, these alterations might reflect changes in the capacity of processing and/or presenting antigens by the DC.

The effects of aging on DC phenotype and function have been investigated, but the results are still controversial.

Correspondence: W.M.S.C. Tamashiro, Departamento de Microbiologia e Imunologia, Instituto de Biologia, UNICAMP, Rua Monteiro Lobato, 255, 13083-862 Campinas, SP, Brasil. Fax: +55-19-3521-6276. E-mail: wirlatam@unicamp.br

Received July 8, 2009. Accepted November 12, 2009. Available online November 27, 2009. Published January 11, 2010. 
There are reports indicating that $D C$ derived from the peripheral blood of humans do not show significant phenotype or functional alterations with aging (13). On the other hand, DC differentiated in vitro from precursors obtained from the bone marrow of old mice show an increased secretion of $\mathrm{IL}-10$ and a reduced secretion of tumor necrosis factor alpha (TNF- $\alpha$ ) and IL- 6 after stimulation with lipopolysaccharide compared to the DC obtained from young mice (14).

Besides aging, genetic background can also influence the susceptibility to induction or maintenance of oral tolerance $(11,15-19)$. Several murine models have been developed to study the phenomenon of central tolerance, and deletion of autoreactive clones of lymphocytes is the main mechanism involved (20-22). About $70-75 \%$ of all thymocytes from the DO11.10 mouse bear the transgenic T-cell receptor (TCR)$\alpha-\beta$ and chains that recognize the ovalbumin (OVA) peptide 323-339 presented by the major histocompatibility complex $(\mathrm{MHC}) \mathrm{I}-\mathrm{A}^{\mathrm{d}}$. The administration of the antigen peptide by the intraperitoneal route led to a rapid deletion of immature thymocytes, $\mathrm{CD}^{+} \mathrm{CD} 8^{+} \mathrm{TCR}^{\text {low }}$ cells, which were reduced to 15 to $20 \%$ (20). The intake of OVA plus anti-IL-12 enhances apoptosis in peripheral lymphoid organs of DO11.10 (23). However, data from our laboratory have shown that the D011.10 mice did not become tolerant upon continuous feeding with OVA (24). We also showed that, unlike the DC from BALB/c mice, DC from young transgenic mice that had ingested OVA were as efficient as naive DC or DC from immunized mice in inducing proliferation and secretion of cytokines by naive T cells (24).

In the present study, we investigated the effects of aging and oral tolerance on the expression of CD80 and CD86 surface markers by DC and on the ability of these cells to stimulate the proliferation of naive $T$ cells obtained from BALB/c and OVA transgenic (DO11.10) mice, and to induce cytokine production in co-cultures of DC and T cells.

\section{Material and Methods}

\section{Mice}

TCR OVA-specific transgenic mice (clone DO11.10) (20) and BALB/c mice were supplied by the Multi-Institutional Center for Biological Investigation of the State University of Campinas. Mice were housed under pathogen-free conditions and fed a diet of autoclaved food and water. BALB/c mice were classified into five age groups ( $N=5$ in each group): young ( 8 weeks of age), adults (20 weeks of age), middle-aged (40 weeks of age), old (60 weeks of age), and very old ( 80 weeks of age) mice based on the results of previous research on age-related antibody and cytokine decrease (10). The study was approved by the Institutional Ethics Committee for Animal Experimentation (Protocol \#594-1).

\section{Reagents}

Type $\mathrm{V}$ bovine serum albumin (BSA), 35\% BSA solution, and type VI OVA(Conalbumin) were purchased from Sigma Chemical Co. (USA). Ovalbumin for oral tolerization was purchased from Rhoster Indústria e Comércio Ltda. (Brazil). Rabbit anti-mouse antibody was prepared and conjugated to type IV horseradish peroxidase (HRPO, Sigma) in our laboratory. The following antibodies were purchased: clone HL-3 (anti-mouse CD11c-phycoerythrin (PE) conjugate; BD Pharmingen, USA), clone TIB229 (anti-class II MHCfluorescein isothiocyanate (FITC) conjugate; prepared in our laboratory), clone 16-10A1 (anti-CD80-FITC; BD Pharmingen), clone GL1 (anti-CD86-FITC; BD Pharmingen), clone 145-2C11 (anti-CD3-PE; BD Pharmingen), clone L3T4 (anti-CD4-FITC; BD Pharmingen), and isotype controls for cytometry assays (BD Pharmingen).

\section{Induction of tolerance and immunization}

$B A L B / c$ mice of each age group were immunized or tolerized as described elsewhere (24). Briefly, mice were immunized by the intraperitoneal (ip) route with $10 \mathrm{mg}$ OVA $+1 \mathrm{mg}$ aluminum hydroxide in saline, and 14 days later they were boosted with $10 \mathrm{mg}$ OVA. For tolerance induction, mice received OVA ( $4 \mathrm{mg} / \mathrm{mL}$ ) in drinking water for 7 consecutive days. One week later, the mice were challenged ip with 10 mg OVA + $1 \mathrm{mg}$ aluminum hydroxide and, after 2 weeks, they were given a booster of $10 \mathrm{mg}$ OVA in saline. Seven days after the last procedure, immunized, tolerized and control (naive) mice were bled and the sera were separated for antibody detection. Mice were then killed to isolate DC, as described below.

\section{Antibody assays}

Antibody titers to OVA were determined by a standard enzyme-linked immunosorbent assay (ELISA) using an automatic ELISA reader (Multiskan II, MS, Labsystem, Finland) as described elsewhere (24). Microtiter plates (Falcon, Becton-Dickinson, USA) were coated with OVA by adding $50 \mu \mathrm{L}$ of the protein solution $(20 \mu \mathrm{g} / \mathrm{mL}$ in carbonate/bicarbonate buffer, $\mathrm{pH}$ 9.6) to each well and incubating the plates for $1 \mathrm{~h}$ at $37^{\circ} \mathrm{C}$ and then overnight at $4^{\circ} \mathrm{C}$. The wells were washed with phosphate-buffered saline (PBS) containing $0.05 \%$ Tween 20 (PBS-T) and then blocked with $5 \%(\mathrm{w} / \mathrm{v})$ skimmed milk in PBS (PBS-SM) for $1 \mathrm{~h}$ at $37^{\circ} \mathrm{C}$. After washing, the plates were incubated for $1 \mathrm{~h}$ at $37^{\circ} \mathrm{C}$ with mouse serum samples diluted from 1:100 to $1: 12,800$ in PBS. After further washing with PBS-T, the plates were incubated with a rabbit anti-mouse immunoglobulin-HRPO conjugate $(275 \mathrm{ng} / \mathrm{mL})$. Sixty minutes later, all reagents were removed by washing and $50 \mu \mathrm{L}$ freshly prepared substrate $(0.04 \%$ ortho-phenylenediamine and $0.03 \%$ $\mathrm{H}_{2} \mathrm{O}_{2}$ in $50 \mathrm{mM}$ citric acid/di-sodium hydrogen phosphate buffer, pH 5.5) was added to each well. After $30 \mathrm{~min}$ in the dark, $25 \mu \mathrm{L} 4 \mathrm{~N} \mathrm{H}_{2} \mathrm{SO}_{4}$ was added to the wells to stop the reaction and the absorbances were read at $492 \mathrm{~nm}$. The results are reported as scores obtained by means \pm SEM of the absorbance values of serum dilutions from 1:100 to 


\section{$1: 12,800$ of each mouse.}

\section{DC enrichment}

Spleen DC-enriched populations were obtained as previously described (24) from BALB/c mice of 8, 20, 40, 60, and 80 weeks of age. Briefly, spleen cells of BALB/c mice were resuspended in a $35 \% \mathrm{BSA}$ solution (density of 1.08 $\mathrm{g} / \mathrm{mL}$ ) and centrifuged at $4000 \mathrm{~g}$ for $40 \mathrm{~min}$ at $4^{\circ} \mathrm{C}$. Cells collected from the interface were transferred to a plastic dish and incubated for $90 \mathrm{~min}$. Non-adherent cells were removed by washing, and the monolayer was incubated for an additional $18 \mathrm{~h}$ in the presence of OVA (Conalbumin, $500 \mu \mathrm{g} / \mathrm{mL}$ ). The DC detached spontaneously after this period of culture, and this enrichment was followed by flow cytometry (FACScalibur, Becton-Dickinson) using DC markers anti-CD11 $c_{\alpha c h a i n}$ APC (clone HL-3; BD Pharmingen), anti-class II MHC PE (clone M5/114.15.2; Miltenyi Biotec, Germany), anti-CD80 FITC (14-10A1; BD Pharmingen), and anti-CD86 FITC (GL1; BD Pharmingen). Amplification and compensation were determined by the examination of unlabeled cells, and analyses were carried out using the Cell Quest software (Becton-Dickinson). Data are reported as percent positive cells and geometric mean fluorescence intensity. Enriched DC preparations contained approximately $80 \%$ class II $\mathrm{MHC}^{+}, 60 \% \mathrm{CD} 11 \mathrm{c}^{+}, 30 \% 33 \mathrm{D} 1^{+}$, and $13 \% \mathrm{CD}^{205^{+}}$cells.

\section{T cell enrichment}

The $\mathrm{T}$ cell populations were enriched from spleens of 8-week-old naive BALB/c or DO11.10 transgenic mice using the protocol of adhesion to nylon wool, as described previously (24). T cell enrichment was monitored by flow cytometry, and the cell suspensions obtained contained approximately $75 \% \mathrm{CD}^{+}$and $50 \% \mathrm{CD}^{+}$cells. T CD4 ${ }^{+}$ cells from naive DO11.10 mice were $80-90 \% \mathrm{KJ} 1.26$ positive.

\section{T cell antigen-specific proliferation}

T cell proliferation assays were carried out as described elsewhere (24). Briefly, T cells $\left(1 \times 10^{6}\right.$ cells/well) and DC $\left(5 \times 10^{4}\right.$ cells/well) were co-cultured in flat-bottomed 96-well plates in the presence of the antigen $(500 \mu \mathrm{g} /$ $\mathrm{mL}$ OVA) for $96 \mathrm{~h}$, and supernatants (half volume) were collected for cytokine determination. -[4,5-Dimethyltiazol2-yl] diphenyltetrazolium bromide solution (MTT, Sigma) was added to the cultures ( $5 \mathrm{mg} / \mathrm{mL} ; 10 \mu \mathrm{L} /$ well) and the plates were incubated for an additional $4 \mathrm{~h}$. After dissolving formazan crystals, absorbance at $540 \mathrm{~nm}$ was measured with an ELISA reader.

\section{Cytokine measurement}

Cytokines were determined in the supernatants of the co-cultures of $\mathrm{T}$ cells and DC using commercial ELISA tests for IL-1, IL-2, IL-4, IL-10, interferon gamma (IFN- $y$ ), and TGF- $\beta$ (BD Pharmingen) according to manufacturer instructions. Absorbance was read at $450 \mathrm{~nm}$, with the wavelength of $540 \mathrm{~nm}$ used for correction.

\section{Statistical analysis}

One-way ANOVA followed by the Bonferroni test was applied to compare the different experimental groups, with the level of significance set at $\mathrm{P}<0.05$.

\section{Results}

Influence of age on the humoral immune response of mice

The humoral immune response of BALB/c mice $(8,20$, 40,60 , and 80 weeks of age) was investigated as a function of oral treatment with OVA followed by an ip challenge or ip immunization, and the levels of specific serum antibodies were determined by ELISA. Figure 1 summarizes the results obtained in these experiments. The mice treated only with an ip injection of OVA produced specific antibodies at significantly higher levels than non-immunized control animals, although a marked age-dependent reduction in these levels was observed. The mice of all ages evaluated became tolerant to OVA after voluntary ingestion of the protein, presenting significantly lower levels of anti-OVA antibodies compared to ip-treated mice $(P<0.05)$. No significant differences in serum antibody levels produced by tolerant animals of the different age groups were observed.

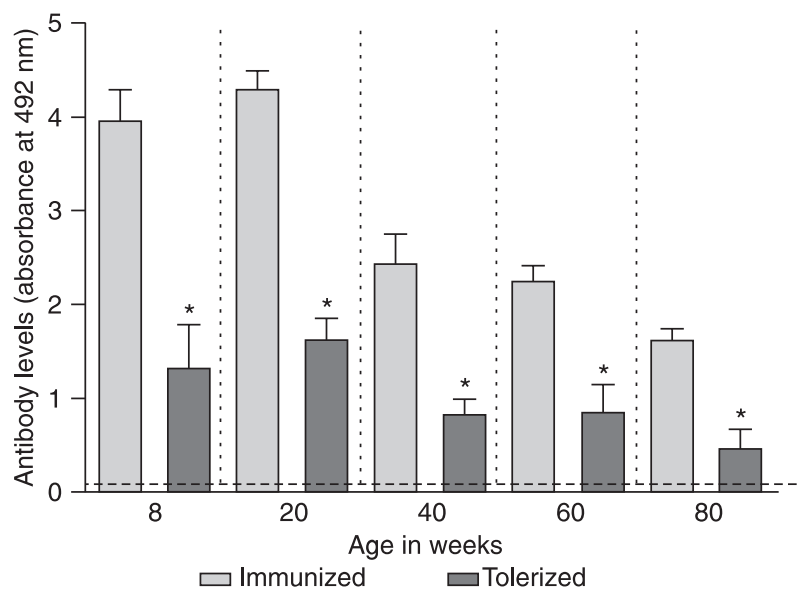

Figure 1. Effect of age and route of ovalbumin (OVA) administration on antibody production by BALB/c mice. Immunoglobulin G-specific antibodies were detected in sera of 8-, 20-, 40-, 60and 80 -week-old BALB/c mice ( $\mathrm{N}=5$ in each group) after 7 consecutive days of ingestion (dark gray bars) or non-ingestion (light gray bars) of a $4-\mathrm{mg} / \mathrm{mL}$ OVA solution. All mice were challenged twice intraperitoneally with OVA and sera were collected 7 days later. Antibodies were measured by ELISA, with each column indicating means \pm SEM of individual running sums of absorbance readings of serum dilutions from 1:100 to $1: 12,800$. Horizontal dashed line indicates the absorbance reading in control serum. Data are representative of three separate experiments $\left({ }^{*} P<0.05\right.$ compared to non-ingestion of OVA; one-way ANOVA followed by the Bonferroni test). 


\section{Influence of age and immunological status on DC activity}

Enriched DC preparations from the spleen of BALB/C mice $(8,20,40,60$, and 80 weeks of age), both tolerant and immune to OVA, were evaluated regarding the expression of CD80 and CD86 using flow cytometry. No alteration was observed in the percent of cells expressing CD80 in DC from the different experimental groups studied (data not shown). As depicted in Figure 2, the percents of CD86 ${ }^{+}$ cells were more reduced in DC isolated from the tolerant mice, and also decreased as a function of aging. Similarly, the expression of the CD86 marker suffered a reduction related to age and to type of immunization (Figure 2).

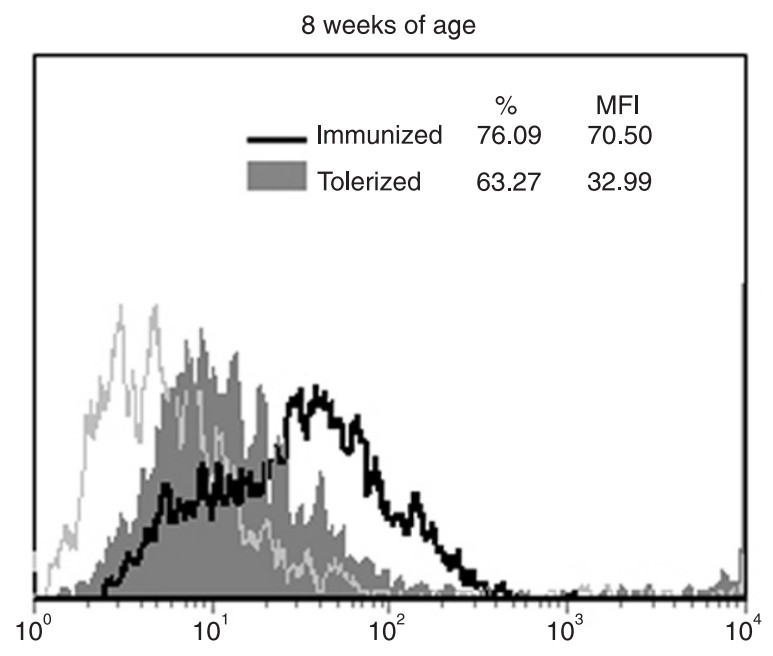

60 weeks of age

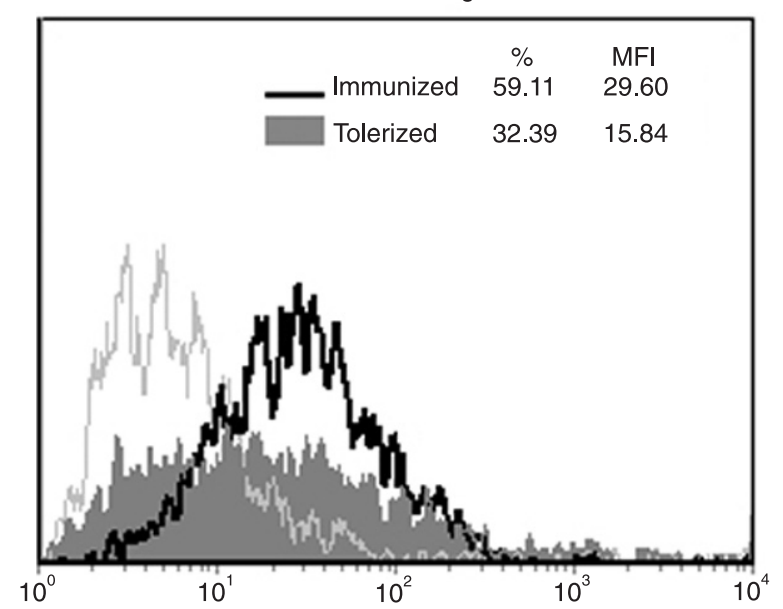

The DC from BALB/c mice of different ages immunized with OVA either orally or ip were used in tests involving antigen presentation to naive T lymphocytes obtained from young BALB/C and DO11.10 mice; DC from naive mice were used as controls. The T/DC co-cultures were conducted in the presence of $500 \mu \mathrm{g} / \mathrm{mL}$ OVA for 4 days. The proliferation of T lymphocytes and the production of Th1 and Th2 cytokines were then evaluated. The results of these tests are summarized in Figure 3. T lymphocytes obtained from BALB/c mice (panelA) and DO11.10 mice (panel B) showed significantly higher proliferation rates when cultivated with DC obtained from mice up to 40 weeks of age treated ip with OVA, than cells cultured in the presence of DC from

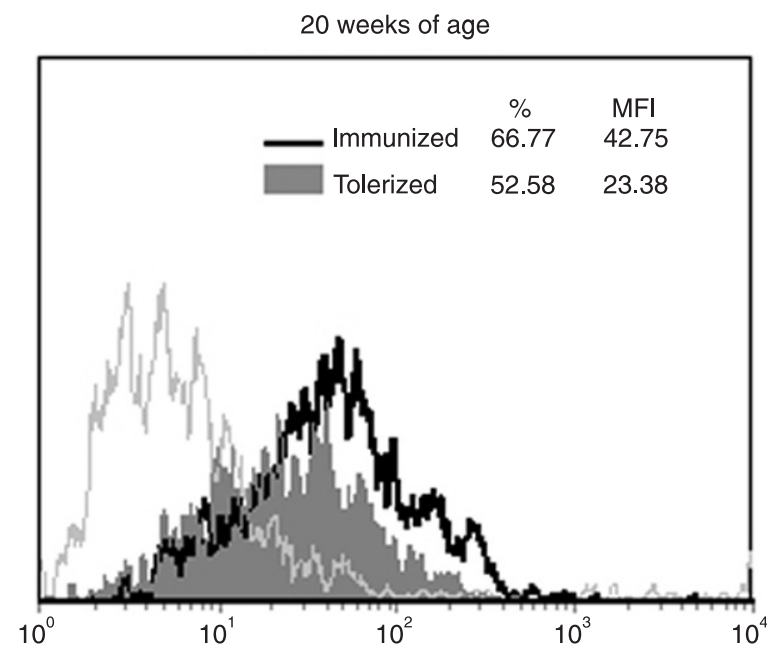

80 weeks of age

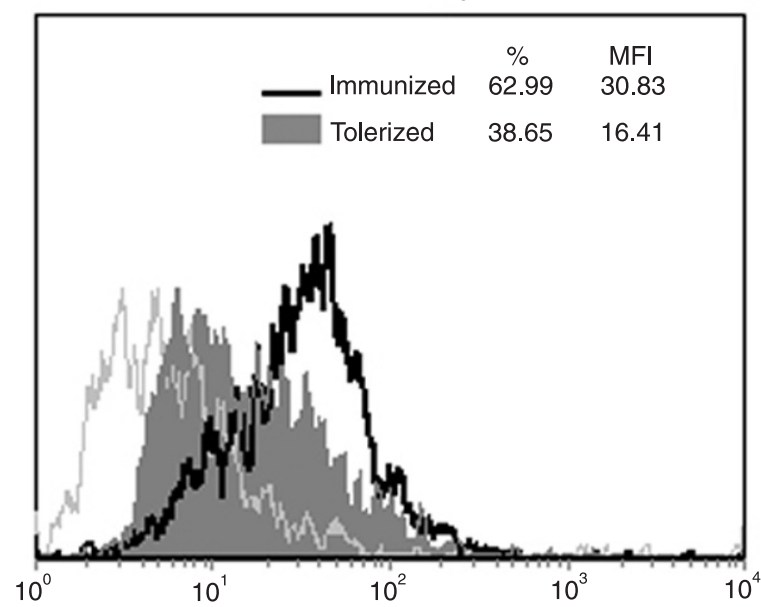

Figure 2. Age-related changes in CD86 surface marker expression in dendritic cells (DC) from immunized and tolerant BALB/c mice. An enriched preparation of spleen DC from BALB/c mice of $8,20,60$, and 80 weeks of age ( $N=5$ in each group) after ingestion of a 4-mg/mL ovalbumin (OVA) solution for 7 consecutive days (tolerized) or not (immunized), followed by an intraperitoneal challenge was used for the study. Enriched DC suspensions were cultured with OVA for $18 \mathrm{~h}$, labeled with an anti-CD86-FITC antibody and analyzed by flow cytometry. Data represent the percentage of CD86-positive cells (\%) and the geometric mean fluorescence intensity (MFI) of all pooled cells harvested after overnight culture over background staining with an isotype-matched control (gray line). Results are representative of two separate experiments pooled from 5 mice. 
non-immunized mice. T cell proliferation was significantly reduced in cultures carried out with $\mathrm{DC}$ collected from mice up to 40 weeks of age that ingested OVA compared to DC from animals immunized ip. DC from non-immune mice of all the age ranges examined were equally capable of stimulating the proliferation of naive T lymphocytes cultivated in the presence of OVA.

The levels of IFN-y and IL-4 were increased in cocultures carried out with DC from either immunized or tolerized mice up to 20 weeks of age. However, the levels of these cytokines were significantly lower $(P<0.05)$ when DC were obtained from BALB/c mice tolerant to OVA (Figure 4) compared to DC from ip-immunized mice, at least when DC were obtained from mice up to 40 weeks of age. At the time of their removal, the supernatants showed no significant differences in IL-2 levels either in relation to the type of immunization or to the age of the DC donors (data not shown).

The levels of IL-10 in the supernatants of cocultures using DC from immunized mice showed an age-dependent increase up to the age of 40 weeks. The co-cultures with DC from BALB/c mice tolerant to OVA showed significantly lower IL-10 levels than did those with the cells of immune BALB/c mice, independently of the age range analyzed (Figure 5, panels $A$ and $B$ ).

On the other hand, TGF- $\beta$ secretion increased in the supernatants of $T$ cells from both BALB/c and DO11.10 animals cultured in the presence of tolerant DC from young BALB/c mice (up to 8 weeks of age), but not when the co-cultures included DC collected from older mice or from those immunized ip with OVA (Figure 5, panels $\mathrm{C}$ and $\mathrm{D}$ ).

The secretion of IL-1 did not suffer significant changes in co-cultures with DC from tolerant or immunized mice. However, an age-dependent increase in the level of this cytokine was found when DC were obtained from mice up to the age of 60 weeks (Figure 6).

\section{Discussion}

Various literature reports have shown alterations in the immune response as a function of age $(25,26)$, but few have been concerned with the effects of aging on the DC in the context of tolerance or immunity (for a review, see Ref. 27). In the present study, we evaluated the immune responses of BALB/c mice ranging in age from young (8 weeks old) to very old (80 weeks old).

We found that middle-aged mice (40 weeks old) already revealed a diminished humoral immune response, as shown by the levels of anti-OVA antibodies, which were significantly lower than in younger animals after parenteral administration of the antigen. These results suggest that the establishment of immunity is easier in younger animals, supporting previous literature data $(10,24,28,29)$. Tolerance was well preserved in all groups of mice studied. However, the differences in the antibody levels of immunized and tolerized mice decreased with advancing age. Literature data show that the capacity of becoming tolerant to an orally administered antigen is better preserved in younger animals, but that some degree of tolerance can be induced in very old animals $(11,15,16,19)$.

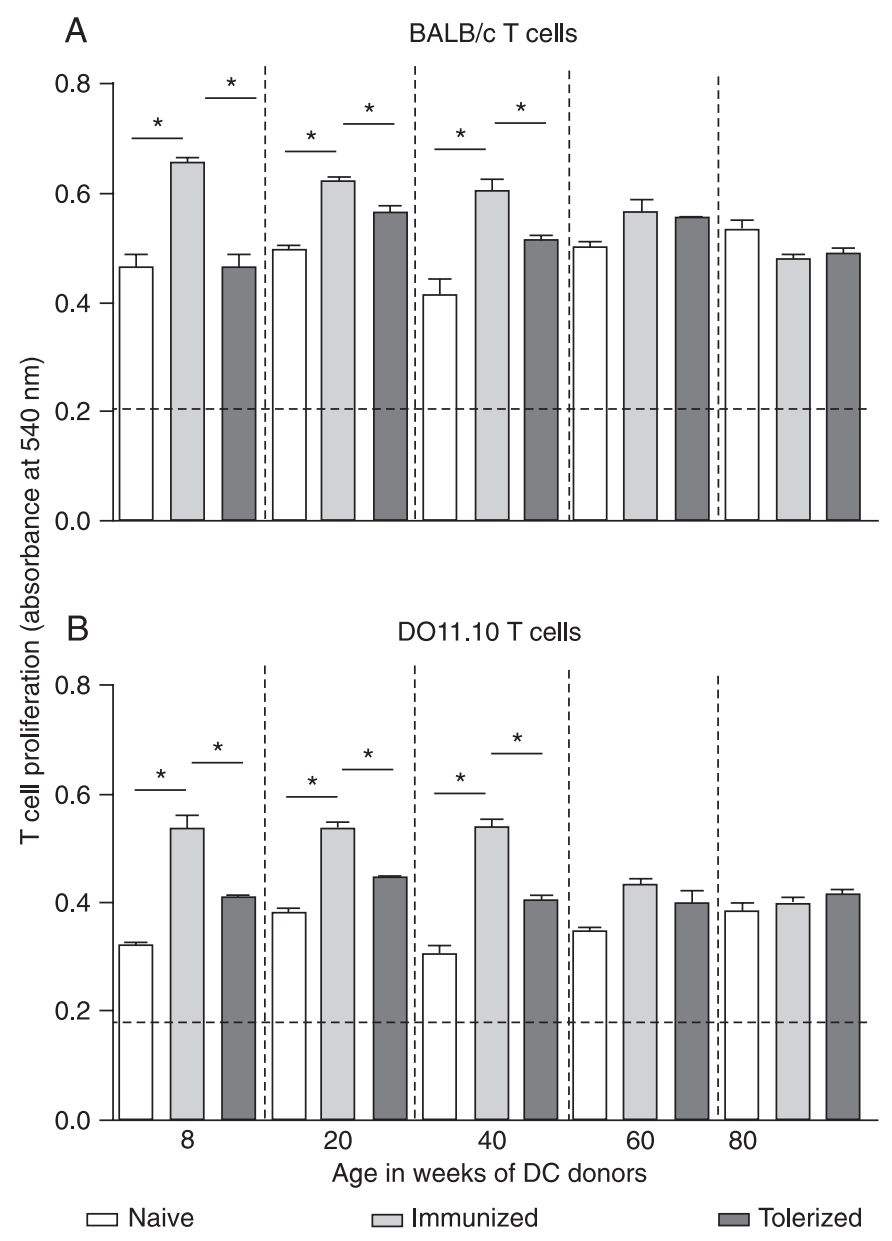

Figure 3. Influence of age and regimen of antigen administration on dendritic cell (DC)-induced $T$ cell proliferation. Data are reported as means \pm SEM absorbance observed in cultures of T cells enriched from a pool of spleens of 5 BALB/c (Panel A) and 5 DO11.10 (Panel B) mice in the presence of DC from 8-, 20-, 40-, 60- and 80-week-old BALB/C mice ( $\mathrm{N}=5$ in each group) that had ingested (dark gray bars) or not (light gray bars) an ovalbumin (OVA) solution $(4 \mathrm{mg} / \mathrm{mL})$ and that were challenged intraperitoneally with OVA. The open columns indicate T-cell proliferation in the presence of $D C$ from naive mice and the horizontal dashed line indicates T cells cultured in the absence of DC. Co-cultures were stimulated with $500 \mu \mathrm{g} / \mathrm{mL}$ OVA. Proliferation was measured by -[4,5-dimethyltiazol-2-yl] diphenyltetrazolium bromide (MTT) staining assays carried out in triplicate. Data are representative of three separate experiments ( ${ }^{*} \mathrm{P}<0.05$ indicated by the horizontal lines on top of the columns; one-way ANOVA followed by the Bonferroni test). 
DC are fundamental for the development of immunity or tolerance to protein antigens. The expression of class II $\mathrm{MHC}$ molecules, co-stimulatory molecules CD80 and CD86, as well as the production of cytokines such as IL-12 by DC, play an important role in the response to inflammatory agents present in the environment, such as microbial antigens. On

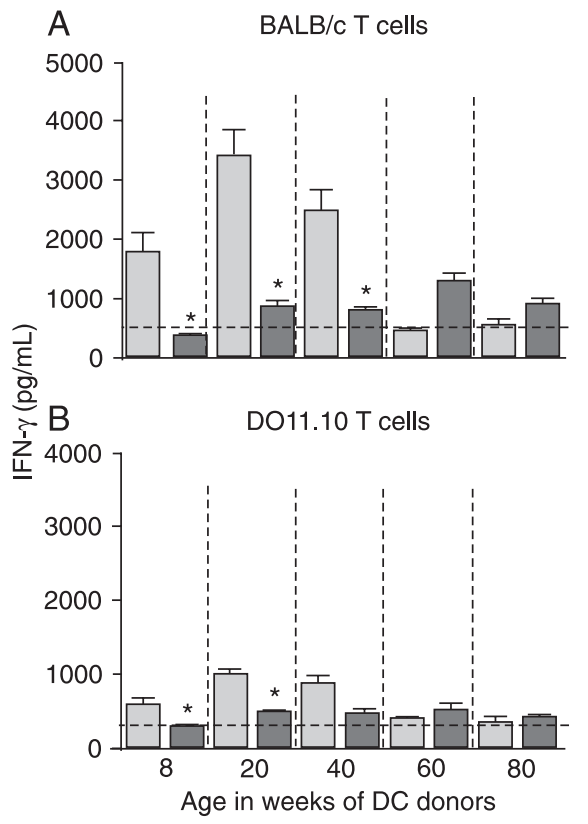

$\square$ Immunized

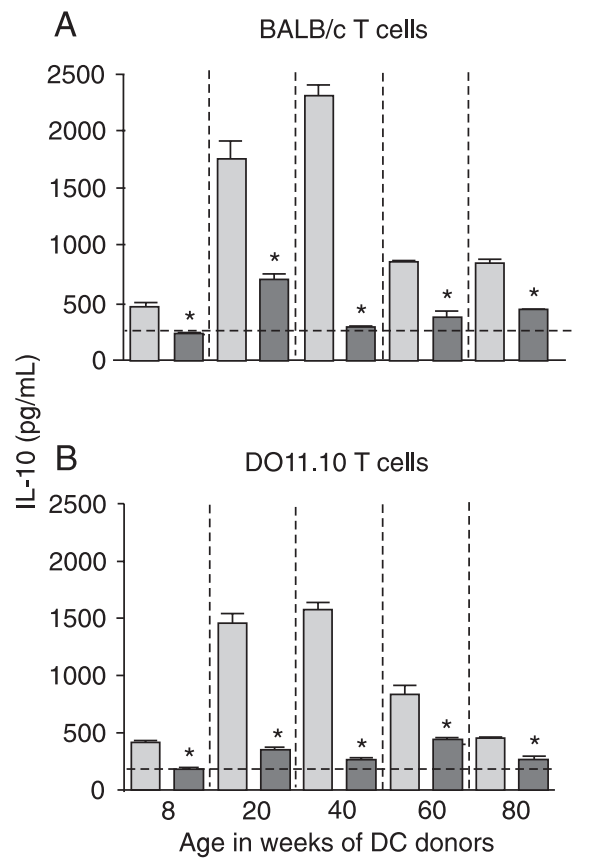

$\square$ Immunized

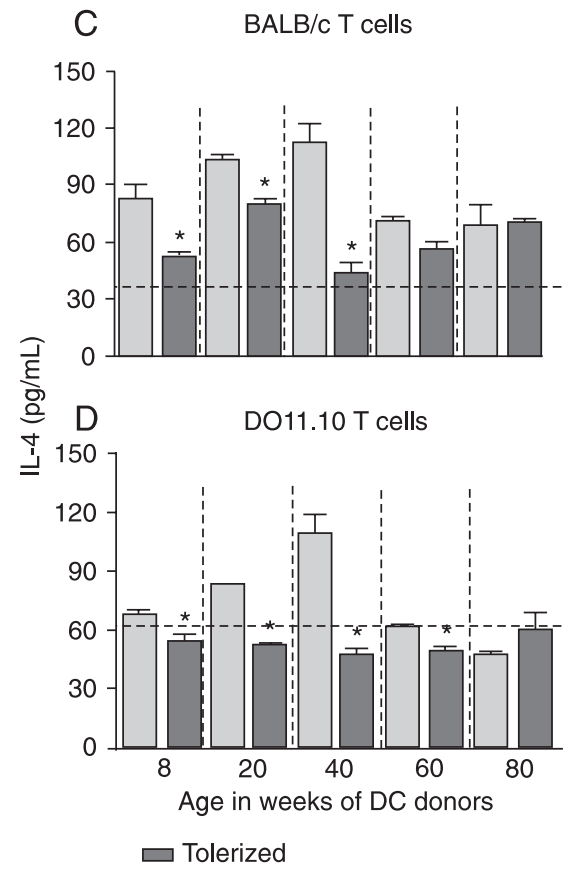

Figure 4. Production of IFN-Y and IL-4 by dendritic cell (DC)/T cell co-cultures: influence of age and form of antigen administration on DC donors. Detection of IFN-Y (Panels A and B) and IL-4 (Panels $C$ and $D$ ) in supernatants of $T$ cells enriched from a pool of spleens of $5 \mathrm{BALB} / \mathrm{c}$ (Panels A and C) and 5 D011.10 (Panels $B$ and D) mice co-cultured with DC from BALB/c mice of $8,20,40,60$, and 80 weeks of age ( $N=5$ in each group) that ingested (dark gray bars) or did not ingest (light gray bars) an ovalbumin (OVA) solution ( $4 \mathrm{mg} / \mathrm{mL}$ ) and that were challenged intraperitoneally with OVA. Cultures were stimulated with $500 \mu \mathrm{g} /$ $\mathrm{mL}$ OVA for $96 \mathrm{~h}$, and cytokine levels in the supernatants were determined by ELISA. Data are representative of three separate experiments, each carried out in triplicate. Horizontal dashed lines indicate cytokine production by $\mathrm{T}$ cells cultured in the absence of DC ( ${ }^{*} \mathrm{P}$ $<0.05$ compared to non-ingestion of OVA; one-way ANOVA followed by the Bonferroni test).

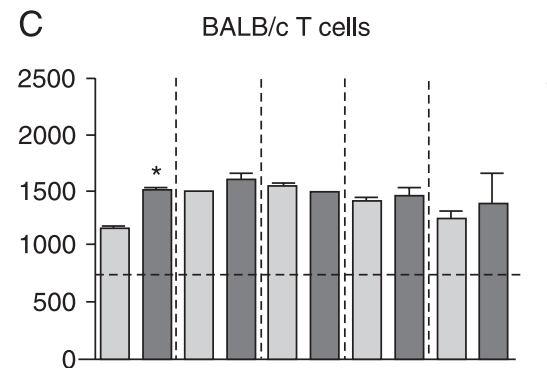

Figure 5. IL-10 and TGF- $\beta$ production by dendritic cell $(\mathrm{DC}) / T$ cell co-cultures: influence of age and regimen of antigen administration on DC donors. Detection of IL-10 (Panels A and B) and TGF- $\beta$ (Panels $C$ and $D$ ) in supernatants of $T$ cells enriched from a pool of 5 spleens of BALB/c (Panels A and C) and 5 DO11.10 (Panels B and D) mice co-cultured with $\mathrm{DC}$ from BALB/C mice of $8,20,40,60$, and 80 weeks of age ( $\mathrm{N}=5$ in each group) that ingested (dark gray bars) or did not ingest (light gray bars) an ovalbumin (OVA) solution $(4 \mathrm{mg} / \mathrm{mL})$ and were intraperitoneally challenged with OVA. Cultures were stimulated with $500 \mu \mathrm{g} /$ $\mathrm{mL}$ OVA for $96 \mathrm{~h}$, and cytokine levels in the supernatants were determined by ELISA. Data are representative of three separate experiments, each carried out in triplicate. Horizontal dashed lines indicate cytokine production by $T$ cells cultured in the absence of DC $\left({ }^{*} \mathrm{P}\right.$ $<0.05$ compared to non-ingestion of OVA; one-way ANOVA followed by the Bonferroni test). 
the other hand, the participation of DC in the induction of peripheral tolerance seems to depend on the existence of certain tolerogenic factors in the environment in which the immune responses are being processed, such as IL-10 and TGF- $\beta$ (for reviews, see Refs. 3,30). Numerous data in the literature show the involvement of immature DC in the establishment of tolerance in the presence of exogenous antigens, especially dietary proteins $(3,30)$. However, there is evidence that mature DC can also induce peripheral tolerance in specific $T$ cells that have escaped negative selection (2). In the present study, we have investigated the capacity of mature spleen DC from orally or ip-treated mice to maintain the antigen-specific proliferation of naive T cells, as well as the production of cytokines in T/DC co-cultures. We observed that DC collected from mice tolerant to OVA were able to present antigens to naive $\mathrm{T}$ lymphocytes, although in somewhat reduced levels compared to those of animals immunized ip.

The literature shows that the numbers and functions of DC are altered during aging (for a review, see Ref. 27). In this regard, it has been shown that the number of DC and follicular DC found in Peyer's patches are more reduced in older individuals than in younger ones $(27,31,32)$. In addition, the proliferative response and production of cytokines by $\mathrm{TCD}^{+}$spleen lymphocytes from tolerant young mice are lower than those of older mice (31). Corroborating literature data, the results obtained here show that DC from immunized and tolerized young mice (8-40 weeks old) differed significantly in their capacity to activate $\mathrm{T}$ lymphocytes. However, DC from either immunized or tolerized older mice present an equally reduced capacity to sustain $\mathrm{T}$ cell proliferation.

We observed in the present study that the production of IFN-y, IL-4 and IL-10 by naive T lymphocytes was affected by both the immune status and age of DC donors. The levels of these cytokines were higher in the co-cultures carried out with DC from young to middle aged immunized mice than in those with DC from tolerant mice, indicating that oral administration of OVA can induce a tolerogenic phenotype in DC. In agreement, TGF- $\beta$ levels were increased in co-cultures carried out with $\mathrm{DC}$ from tolerized younger (8 weeks old) mice. It is well known that oral administration of the antigen leads to active suppression of the immune response by various types of regulatory cells such as Th3, regulatory $\mathrm{T}$ type $1\left(\mathrm{CD} 4^{+} \mathrm{CD} 25^{+}\right)$and $\mathrm{CD} 4^{+} \mathrm{CD} 45 \mathrm{Rb}$ low cells, which secrete TGF- $\beta(3,32-35)$, as well as TCD4 ${ }^{+}$ latency-associated peptide (LAP) ${ }^{+}$cells that express TGF- $\beta$ in a latent form on the membrane of the cells (36). Indeed, we observed that DC from tolerized young mice can enable naive $\mathrm{T}$ cells to produce TGF- $\beta$, probably by in vitro expansion of naturally occurring regulatory $T$ cells. Literature data suggested that IL-1 production by DC is important to initiate the cascade of inflammatory cytokines that influence the generation of Th1 cells (37). Interestingly, we observed that IL-1 was produced at low levels in co-cultures of DC
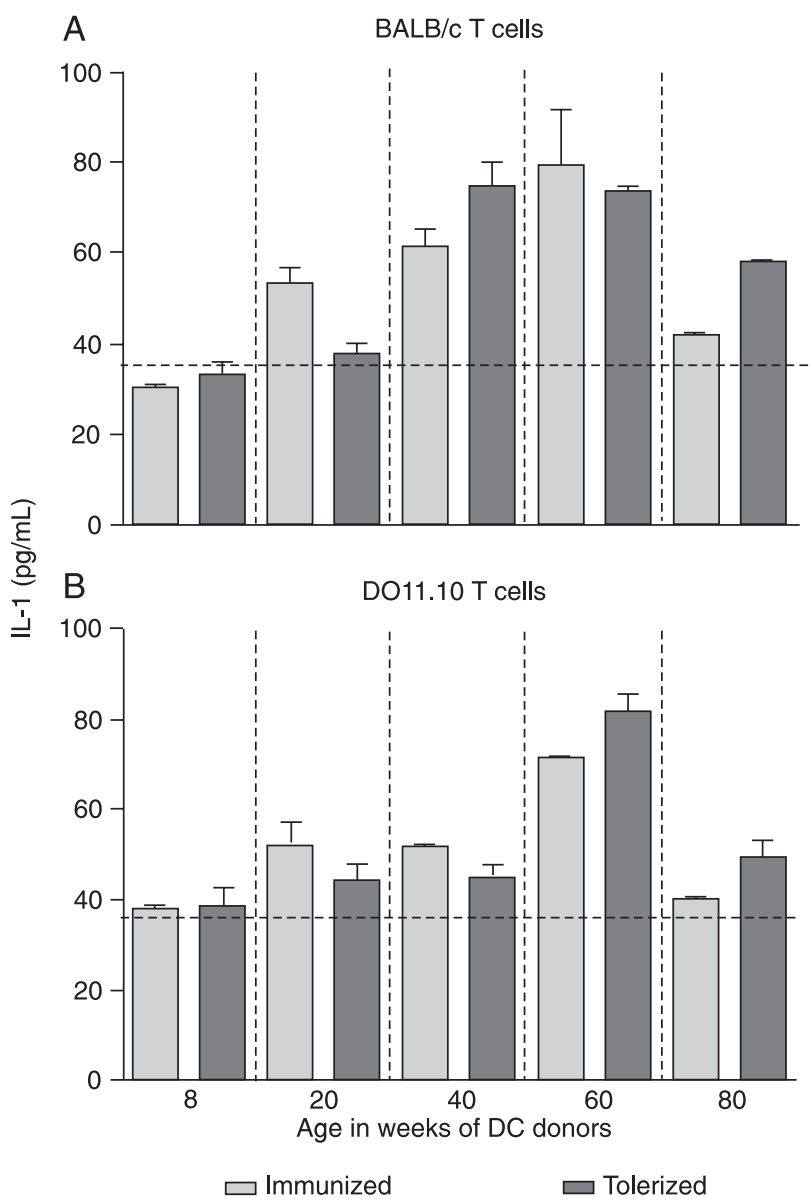

Figure 6. IL-1 production by dendritic cell (DC)/T cell co-cultures: influence of age and regimen of antigen administration on DC donors. Detection of IL-1 in supernatants of T cells enriched from a pool of 5 spleens of BALB/c (Panel A) and 5 DO11.10 (Panel B) mice co-cultured with DC from BALB/c mice of $8,20,40,60$, and 80 weeks of age ( $N=5$ in each group) that ingested (dark gray bars) or did not ingest (light gray bars) an ovalbumin (OVA) solution $(4 \mathrm{mg} / \mathrm{mL})$ and were intraperitoneally challenged with OVA. Cultures were stimulated with $500 \mu \mathrm{g} / \mathrm{mL}$ OVA for $96 \mathrm{~h}$, and cytokine levels in the supernatants were determined by ELISA. Data are representative of three separate experiments, each carried out in triplicate. Horizontal dashed lines indicate cytokine production by $\mathrm{T}$ cells cultured in the absence of $\mathrm{DC}\left({ }^{*} \mathrm{P}<0.05\right.$ compared to non-ingestion of OVA; one-way ANOVA followed by the Bonferroni test).

from young mice, and did not suffer significant changes as a result of tolerance or immunization. In addition, we observed an age-dependent increase in IL-1 levels in the absence of changes in TGF- $\beta$ levels in experimental groups aged 20 to 60 weeks. Taken together, these results suggest that naive $T$ cells produce the secreted form of TGF- $\beta$ only in the presence of low levels of IL-1, and this may account for the establishment of oral tolerance in the early stages 
of postnatal development. In older mice, the secreted form of TGF- $\beta$ may play a secondary role in this process.

Our data showed that oral treatment with OVA resulted in a reduction in the frequency of $\mathrm{CD}^{2} 6^{+}(\mathrm{B} 7.2)$ spleen $\mathrm{DC}$, as well as in the expression of this molecule. No change was observed in the frequency of cells expressing CD80 or in the expression of this molecule (data not shown). The literature shows controversial results regarding the role of CD86 in tolerance. There are data showing that the administration of anti-CD86 antibodies results in a blocking of the induction of tolerance in wild mice (7), but later research by the same group showed that it was possible to induce tolerance to a glycoprotein of myelin in knock-out CD86 mice (38).

We also observed an age-dependent reduction in CD86 expression, but not in the frequency of cells expressing this molecule. The literature is poor regarding the effects of aging on the expression of CD80 and CD86 co-stimulatory molecules. In this regard, Haruna et al. (39) did not find changes in the percentage of spleen $D C$ expressing the CD80 and CD86 markers in studies conducted with senescence-accelerated prone mice. However, Shurin et al. (40) showed that spleen DC and DC from the bone

\section{References}

1. Kalinski P, Hilkens CM, Wierenga EA, Kapsenberg ML. Tcell priming by type- 1 and type-2 polarized dendritic cells: the concept of a third signal. Immunol Today 1999; 20: 561567.

2. Hawiger D, Inaba K, Dorsett Y, Guo M, Mahnke K, Rivera M, et al. Dendritic cells induce peripheral T cell unresponsiveness under steady state conditions in vivo. J Exp Med 2001; 194: 769-779.

3. Faria AM, Weiner HL. Oral tolerance. Immunol Rev 2005; 206: 232-259.

4. Ohnmacht C, Pullner A, King SB, Drexler I, Meier S, Brocker $\mathrm{T}$, et al. Constitutive ablation of dendritic cells breaks selftolerance of CD4 T cells and results in spontaneous fatal autoimmunity. J Exp Med 2009; 206: 549-559.

5. Muller G, Muller A, Tuting T, Steinbrink K, Saloga J, Szalma $C$, et al. Interleukin-10-treated dendritic cells modulate immune responses of naive and sensitized T cells in vivo. $J$ Invest Dermatol 2002; 119: 836-841.

6. Steinbrink K, Wolfl M, Jonuleit H, Knop J, Enk AH. Induction of tolerance by IL-10-treated dendritic cells. J Immunol 1997; 159: 4772-4780.

7. Liu L, Kuchroo VK, Weiner HL. B7.2 (CD86) but not B7.1 (CD80) costimulation is required for the induction of low dose oral tolerance. J Immunol 1999; 163: 2284-2290.

8. Kobets N, Kennedy K, Garside P. An investigation of the distribution of antigen fed in tolerogenic or immunogenic forms. Immunol Lett 2003; 88: 147-155.

9. Kishimoto $\mathrm{S}$, Takahama $\mathrm{T}$, Mizumachi $\mathrm{H}$. In vitro immune response to the 2,4,6-trinitrophenyl determinant in aged C57BL/6J mice: changes in the humoral immune response to, avidity for the TNP determinant and responsiveness to marrow of old nude mice show a reduction in the expression of co-stimulatory molecules such as CD86 and class II MHC molecules.

Taken together, the present results show that aging produces alterations in various aspects of the immunity to exogenous antigens, especially in the production of antibodies and the in vitro activity of DC after parenteral or oral immunization. The age-dependent reduction in the expression of the CD86 co-stimulatory molecule in DC may explain, at least in part, the decrease in in vivo and in vitro responses observed here. Although there is a growing interest in the therapeutic use of DC, our results suggest that the clinical applications of these cells may be limited in older individuals.

\section{Acknowledgments}

The authors thank the staff of Hemocentro/UNICAMP for assistance with the flow cytometry assays. Research supported by FAPESP (\#01/08462-6, \#05/51520-8 and \#06/60128-7). P.U. Simioni and L.G.R. Fernandes were recipients of fellowships from FAPESP (\#05/03507-2) and CNPq (\#142333/2005-0), respectively.
LPS effect with aging. J Immunol 1976; 116: 294-300.

10. Simioni PU, Costa EH, Tamashiro WM. Aging reduces the primary humoral response and the in vitro cytokine production in mice. Braz J Med Biol Res 2007; 40: 1111-1120.

11. Moreau MC, Gaboriau-Routhiau V. The absence of gut flora, the doses of antigen ingested and aging affect the long-term peripheral tolerance induced by ovalbumin feeding in mice. Res Immunol 1996; 147: 49-59.

12. Lu YF, Cerny J. Repertoire of antibody response in bone marrow and the memory response are differentially affected in aging mice. $J$ Immunol 2002; 169: 4920-4927.

13. Steger MM, Maczek C, Grubeck-Loebenstein B. Morphologically and functionally intact dendritic cells can be derived from the peripheral blood of aged individuals. Clin Exp Immunol 1996; 105: 544-550.

14. Grolleau-Julius A, Garg MR, Mo R, Stoolman LL, Yung RL. Effect of aging on bone marrow-derived murine CD11c+CD4CD8alpha-dendritic cell function. J Gerontol A Biol Sci Med Sci 2006; 61: 1039-1047.

15. de Faria AM, Ficker SM, Speziali E, Menezes JS, Stransky $B$, Silva Rodrigues $V$, et al. Aging affects oral tolerance induction but not its maintenance in mice. Mech Ageing Dev 1998; 102: 67-80.

16. Wakabayashi A, Utsuyama M, Hosoda T, Sato K, Hirokawa $K$. Differential age effect of oral administration of an antigen on antibody response: an induction of tolerance in young mice but enhancement of immune response in old mice. Mech Ageing Dev 1999; 109: 191-201.

17. Verdolin BA, Ficker SM, Faria AM, Vaz NM, Carvalho CR. Stabilization of serum antibody responses triggered by initial mucosal contact with the antigen independently of oral toler- 
ance induction. Braz J Med Biol Res 2001; 34: 211-219.

18. Faria AM, Ficker SM, Speziali E, Menezes JS, Stransky $B$, Verdolin BA, et al. Aging and immunoglobulin isotype patterns in oral tolerance. Braz J Med Biol Res 1998; 31: 35-48.

19. Lahmann WM, Menezes JS, Verdolin BA, Vaz NM. Influence of age on the induction of oral tolerance in mice and its adoptive transfer by spleen cells. Braz J Med Biol Res 1992; 25: 813-821.

20. Murphy KM, Heimberger AB, Loh DY. Induction by antigen of intrathymic apoptosis of CD4+CD8+TCRlo thymocytes in vivo. Science 1990; 250: 1720-1723.

21. Cibotti R, Kanellopoulos JM, Cabaniols JP, Halle-Panenko O, Kosmatopoulos K, Sercarz E, et al. Tolerance to a selfprotein involves its immunodominant but does not involve its subdominant determinants. Proc Natl Acad Sci U S A 1992; 89: 416-420.

22. Hogquist KA, Jameson SC, Heath WR, Howard JL, Bevan MJ, Carbone FR. T cell receptor antagonist peptides induce positive selection. Cell 1994; 76: 17-27.

23. Marth T, Strober W, Kelsall BL. High dose oral tolerance in ovalbumin TCR-transgenic mice: systemic neutralization of IL-12 augments TGF-beta secretion and T cell apoptosis. $J$ Immunol 1996; 157: 2348-2357.

24. Simioni PU, Fernandes LG, Gabriel DL, Tamashiro WM. Induction of systemic tolerance in normal but not in transgenic mice through continuous feeding of ovalbumin. Scand $\mathrm{J}$ Immunol 2004; 60: 257-266.

25. Makinodan T, Yunis E. Immunology and ageing. In: Good RA, Day SB (Editors), Comprehensive immunology. New York: Plenum Publishing Corporation; 1977. p 1-70.

26. Plowden J, Renshaw-Hoelscher M, Gangappa S, Engleman C, Katz JM, Sambhara S. Impaired antigen-induced CD8 ${ }^{+}$ $T$ cell clonal expansion in aging is due to defects in antigen presenting cell function. Cell Immunol 2004; 229: 86-92.

27. Shurin MR, Shurin GV, Chatta GS. Aging and the dendritic cell system: implications for cancer. Crit Rev Oncol Hematol 2007; 64: 90-105.

28. Borghesi $\mathrm{C}$, Nicoletti C. In vivo and in vitro study of the primary and secondary antibody response to a bacterial antigen in aged mice. Int J Exp Pathol 1995; 76: 419-424.

29. Smith $P$, Dunne DW, Fallon PG. Defective in vivo induction of functional type 2 cytokine responses in aged mice. Eur $J$ Immunol 2001; 31: 1495-1502.

30. Mowat AM, Parker LA, Beacock-Sharp H, Millington OR, Chirdo F. Oral tolerance: overview and historical perspectives. Ann N Y Acad Sci 2004; 1029: 1-8.

31. Fujihashi K, McGhee JR. Mucosal immunity and tolerance in the elderly. Mech Ageing Dev 2004; 125: 889-898.

32. Kato H, Fujihashi K, Kato R, Dohi T, Fujihashi K, Hagiwara $\mathrm{Y}$, et al. Lack of oral tolerance in aging is due to sequential loss of Peyer's patch cell interactions. Int Immunol 2003; 15: 145-158.

33. Friedman A, Weiner HL. Induction of anergy or active suppression following oral tolerance is determined by antigen dosage. Proc Natl Acad Sci U S A 1994; 91: 6688-6692.

34. Groux H, O'Garra A, Bigler M, Rouleau M, Antonenko S, de Vries JE, et al. A CD4 ${ }^{+}$T-cell subset inhibits antigen-specific T-cell responses and prevents colitis. Nature 1997; 389: 737-742.

35. Powrie F, Carlino J, Leach MW, Mauze S, Coffman RL. A critical role for transforming growth factor-beta but not interleukin 4 in the suppression of T helper type 1-mediated colitis by CD45RB(low) CD4 ${ }^{+} \mathrm{T}$ cells. J Exp Med 1996; 183: 2669-2674.

36. Nakamura K, Kitani A, Strober W. Cell contact-dependent immunosuppression by CD4(+)CD25(+) regulatory T cells is mediated by cell surface-bound transforming growth factor beta. J Exp Med 2001; 194: 629-644.

37. Brereton CF, Sutton CE, Lalor SJ, Lavelle EC, Mills KH. Inhibition of ERK MAPK suppresses IL-23- and IL-1-driven IL-17 production and attenuates autoimmune disease. $J$ Immunol 2009; 183: 1715-1723.

38. Gonnella PA, Chen YH, Waldner H, Weiner HL. Induction of oral tolerization in CD86 deficient mice: a role for CD86 and B cells in the up-regulation of TGF-beta. J Autoimmun 2006; 26: 73-81.

39. Haruna H, Inaba M, Inaba K, Taketani S, Sugiura K, Fukuba $\mathrm{Y}$, et al. Abnormalities of B cells and dendritic cells in SAMP1 mice. Eur J Immunol 1995; 25: 1319-1325.

40. Shurin GV, Chatta GS, Tourkova IL, Zorina TD, Esche C, Shurin MR. Regulation of dendritic cell expansion in aged athymic nude mice by FLT3 ligand. Exp Gerontol 2004; 39 : 339-348. 